\title{
EXPERIÊNCIA URBANA E ROMANCE BRASILEIRO
}

\author{
Urban experience and Brazilian novel
}

\section{Fernando Cerisara Gil ${ }^{*}$}

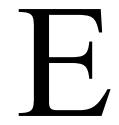

ste artigo se pauta pela seguinte preocupação: de que modo surge, de fato, a representação da experiência urbana em nossa ficção? Para sugerir uma resposta a essa questão, gostaria, antes de tudo, de lembrar uma passagem do já clássico estudo de Roberto Schwarz, chamado "As idéias fora do lugar". Trata-se de um trecho em que Roberto Schwarz compara as articulações de nossas relações sociais e o ritmo de nossa vida ideológica com as articulações que dão forma à vida européia. Lá pelas tantas diz o autor: “.... um latifúndio pouco modificado viu passarem as maneiras barroca, neoclássica, romântica, naturalista, modernista e outras, que na Europa acompanharam e refletiram transformações imensas na ordem social". ${ }^{1}$ Essa passagem surge para mim como uma espécie de súmula, uma formulação em miniatura, precisa e ao mesmo tempo muito brilhante, da complicada e complexa relação entre a literatura brasileira e a nossa vida social. E, por ser precisa e de alto alcance, sem querer, ela parece dizer muito também a respeito do tema em foco.

A observação de Roberto Schwarz de que um latifúndio praticamente intocado viu passar, em diferentes momentos, um leque amplo e variado de experiências estéticas, talvez implicitamente sugira algo da relação entre experiência urbana e o modo particular desta experiência figurar em nossa literatura. Desde a formação do romance brasileiro, a cidade está presente em nossa literatura, ou, pelo menos, é o que a história da literatura e a crítica brasileiras, muitas vezes, nos fazem acreditar desde o momento em que elas fazem a diferenciação entre romance urbano

* Universidade Federal do Paraná

1 SCHWARZ, Roberto. Ao vencedor as batatas. São Paulo: Duas Cidades, 1981. p. 21-22. 
e rural ou regionalista. Lembre-se, por exemplo, do Alencar urbano e do Alencar rural. Claro que muitos dos nossos romances do século XIX, de Joaquim Manuel de Macedo a Machado de Assis, são ambientados em quartos, salões e ruas que se localizam numa cidade, sobretudo no Rio de Janeiro. Entretanto, a idéia-síntese de Roberto Schwarz, de um latifúndio que domina a cena social brasileira, parece, a meu ver, pôr numa chave bastante singular a experiência urbana representada nesses romances. Se formos desdobrar um pouco a fórmula de Roberto Schwarz, vamos logo notar que a noção de latifúndio diz respeito a uma longa experiência histórica, à qual se associam, além da grande propriedade rural, a brutalidade das relações sociais escravistas, mandonismo e dependência econômica do país. Diria então, ainda que esquematicamente, que a formação do romance ou da narrativa brasileira constituiu-se a participar de uma matriz histórica, ou, caso se queira, de uma formação social cujo eixo forte, dominante, estava centrado no campo, no mundo rural, com os seus correlatos sociais acima mencionados (escravidão, mandonismo etc.); além, é claro, do seu quinhão de atraso e de imobilidade que isso tudo determinava numa das pontas do processo social. Em outras palavras, se a literatura, sobretudo o romance, por um lado, é um dos elementos da outra ponta do processo social que traz consigo, em sua forma, traços de atualização, de modernidade, enfim, de ajuste a uma experiência mental, intelectual e cultural mais moderna e mais avançada para os nossos escritores e seus respectivos públicos - público esse rarefeito em nosso contexto, como se sabe -, por outro lado, a tradição romanesca que vai fincando pé por aqui engendra seu modo de ser num horizonte mental e espiritual governado pelo latifúndio, para voltarmos à fórmula de Roberto Schwarz.

Já há estudos fundamentais que procuram dar conta da singularidade formativa do nosso romance do século XIX. Penso nos ensaios de Antonio Candido, "Dialética da malandragem" " "De cortiço a cortiço", além das formulações contidas em Formação da literatura brasileira, que ainda está à espera de desdobramentos; ou ainda os próprios estudos de Roberto Schwarz sobre Machado de Assis e José de Alencar para os quais eu remeto o leitor. Mas gostaria de retirar uma conseqüência dessa relação entre nossa formação romanesca e a matriz latifundiário-escravista que enformou a nossa vida literária. A conseqüência que estou procurando retirar talvez possa ser formulada nos seguintes termos: a experiência urbana figurada no romance brasileiro, do século XIX até mais ou menos as duas primeiras décadas do século $\mathrm{XX}$, se caracteriza e toma sentido a partir de um contorno e de uma lógica social que se define como dominantemente não-urbana, ou seja, a partir de uma experiência social centrada no campo, na vida rural e nas relações de dependência. Não se trata, portanto, de não haver experiência urbana nas narrativas de um José de Alencar, de um Aluísio Azevedo e ou de um Machado de Assis; mas de se tentar 
compreender como a vivência encenada na cidade debate-se com uma forma estética que a todo o momento está a anunciar, a revelar, em alguma instância de sua composição, a compressão, o acanhamento, quando não um certo senso de disparate, de incongruência, de desproporção dos elementos e das coisas ali em jogo.

Se não for forçar a nota, eu diria que boa parte do esforço dos nossos ficcionistas do dezenove, consciente ou inconscientemente, pouco importa, foi dar conta de exprimir uma experiência na cidade que se queria moderna, avançada numa palavra, de dar expressão a uma experiência que se pretendia aos moldes e à norma burguesa de vida. Ao mesmo tempo, entretanto, a enunciação dessa experiência mostra-se diminuída, amesquinhada, ou no mínimo relativizada, pois o seu modo de ser não se define, em grande parte, na esfera da experiência a que procura dar voz, ou seja, a do espaço urbano. Em sua quase totalidade, essa experiência urbana, ficcionalmente representada, sofre os influxos de um andamento social que pode-se dizer que "está fora dela". Simplificando muito, digamos que a experiência da cidade nessa ficção se produz fora da sua órbita na medida em que a nossa experiência social, no conjunto, tem sua matriz prática engendrada no latifúndio-escravista. Estamos aqui, me parece, diante de outro torcicolo cultural ou literário - para se usar uma outra imagem de Roberto Schwarz. Só que agora se trata de um torcicolo interno, se assim posso dizer: sentados juntos a uma escrivaninha em alguma cidade do país, geralmente no Rio de Janeiro ou em São Paulo, nossos escritores procuravam olhar para a cidade, mas viam pulsar nela, num mesmo passo, um travejamento de outra ordem, constituinte de uma certa vivência urbana, mas ao mesmo tempo muito diferente dela.

Quando disse acima que esses romances podem dar feição a vivências na cidade a partir de uma diç̧ão narrativa que vai da experiência amesquinhada ao disparate, não estou querendo imprimir, de todo, um juízo de valor a essas expressões e, por extensão, aos romances que lhes possam corresponder. As relações entre a forma romance que tenta captar e estilizar uma experiência social na cidade e o fato de essa forma ser atravessada e sobredeterminada pela experiência histórica do latifúndio e da escravidão não são boas nem ruins em si. Claro que isso parece ter sido, por um lado, a base de muita frivolidade romanceada, do tipo $A$ moreninha aos romances empostados de nossa belle époque. Por outro, entretanto, quando encontrou o talento de um escritor como Machado de Assis, que soube como ninguém transformar essa espécie de desvantagem histórica em vantagem literária, armou-se um ponto de vista literário poderoso. O Brás Cubas, de Machado, como personagem e narrador, estrutura um ponto de vista de classe em que o "critério burguês, ilustrado e europeu", requerido nos salões cariocas, alterna-se com outro "emanado de nossas relações sociais não-burguesas", como observa o próprio Roberto Schwarz no estudo 
sobre este romance de Machado de Assis. ${ }^{2}$ Sob este aspecto, o romance Memórias póstumas de Brás Cubas constitui uma espécie de ponto alto de resolução literária disso que estou procurando mostrar neste primeiro instante: a dualidade de perspectivas que enseja a representação ficcional de nossas primeiras vivências urbanas formula-se, em Machado, com um vetor literário crítico desse processo. Brás Cubas comete, sim, uma traição de classe: ao narrar-se, o personagem revela a desfaçatez e as instâncias do arbítrio das classes dominantes. ${ }^{3}$ Só que a voz volúvel do narrador machadiano procede, ainda, do latifúndio, da escravidão e de seus correlatos, ainda que necessite para se constituir do quadro estreito e rarefeito de uma certa paisagem urbana, que é por onde se movimenta a trama machadiana. Eu diria, para sintetizar, que a ficção de Machado de Assis é ainda a encenação da grande experiência do latifúndio intocado que transita pelas ruas ainda apertadas e acanhadas da cidade.

Voltando para a observação que serviu como mote inicial deste estudo, talvez já se possa, nesta altura, fazer a seguinte pergunta: se boa parte de nossa produção ficcional - esta boa parte que vai dos primeiros momentos formativos de nosso romance até os primeiros modernistas - foi produzida tendo como matriz de nossa experiência histórica e mental esse latifúndio pouco modificado, em que momento de nossa vida social a matriz histórica do latifúndio deixou de estabelecer as linhas de forças dominantes de nosso andamento literário? Dito de outro modo, em que instante a nossa experiência urbana ficcionalmente representada deixou de ser engendrada por um latifúndio pouco modificado ou por instâncias não-urbanas, por assim dizer?

Quero acreditar que a formulação dessa pergunta traz um problema de fundo importante que merece ser explicitado. Se a diversidade de estilos e formas literárias ao longo do tempo no país, ao contrário do que ocorreu na Europa, não refletiu de fato transformações profundas na ordem social, nem por isso nosso sistema social deixou de se modificar, inserido que estava na ordem mundial do capital. Neste ponto, gostaria de sugerir uma hipótese para tentar explicar o modo como a experiência ficcional urbana deixa de ser sobredeteminada pela experiência do latifúndio. O que chamo de hipótese nem é minha e muito menos é original: seria o esgotamento da experiência rural, latifundiária e patriarcal em si que redefine a representação da experiência urbana em nossa narrativa. Estou chamando a atenção antes de tudo, se não para o fim, pelo menos para o profundo esgotamento de uma

2 SCHWARZ, Roberto. Um mestre na periferia do capitalismo. São Paulo: Duas Cidades, 1990. p. 45 .

3 Ibid., p. 78-79. 
experiência que é essa do latifúndio. Esgotamento esse que situo mais ou menos nos anos de 1930. Pelo menos é por esse período que a nossa literatura vai tomar consciência e vai dar expressão literária a essa virada que estou sugerindo. Nesse momento, a experiência urbana na literatura brasileira se torna de fato relevante, não tanto em razão do processo de urbanização e de modernização pelo qual as cidades brasileiras estavam passando por essa época, mas muito mais em razão do esgotamento ou da crise da experiência da vida rural. Esse esgotamento se torna o eixo central da representação da nossa experiência urbana moderna na ficção e talvez mesmo na poesia.

Penso que ao menos parte daquilo que Antonio Candido chama de fase de pré-consciência do subdesenvolvimento, no seu ensaio "Literatura e subdesenvolvimento", esteja relacionada a essa espécie de trauma histórico causado pelo esgotamento da experiência da vida rural como definidora do campo de força histórico e mental do país. Neste sentido, a passagem da consciência de país novo à consciência de país subdesenvolvido, com o quinhão de pessimismo a que se refere Antonio Candido ${ }^{4}$ neste último caso, me parece não somente determinada pela reflexão que nossos escritores passam a fazer do país à luz da consciência do atraso e do subdesenvolvimento, mas sobretudo por essa espécie de turning point histórico, digamos assim. Se a paisagem nacional, ao longo de nossa história social, não se configura por mudanças profundas, com transformações radicais na ordem social, nem por isso essa paisagem deixa de se modificar, a seu modo e com uma feição muito particular. Trata-se de uma mudança não da dinâmica de classes e das relações sociais que a correspondem, mas de mudança de ênfase no andamento do processo social como um todo que não pode mais se reproduzir predominantemente, ao menos, pela matriz prático-histórico do latifúndio-oligárguico.

Arriscaria a dizer que a consciência moderna brasileira se configura a partir da tomada consciência desse processo traumático. Tratar-se-ia, nesse instante, de uma experiência que redimensionaria o passado histórico e o literário. Tem-se aqui, a meu ver, uma dupla acumulação, histórica e literária, inextricavelmente relacionadas, cuja resultante é aquilo que Antonio Candido chamou, no mesmo ensaio, da criação de um mecanismo de causalidade interna. A idéia de um sistema literário que se determina por relações internas diz respeito, segundo Candido, à “capacidade de (se) produzir obras de primeira ordem, influenciada, não por modelo

4 CANDIDO, Antonio. Literatura e subdesenvolvimento. In: Educação pela noite. São Paulo: Ática, 1987. p. 140-160. 
estrangeiros imediatos, mas por exemplos nacionais anteriores", tornando "inclusive mais fecundos os empréstimos tomadas às outras culturas". ${ }^{5}$

Em síntese, pode-se dizer que a experiência urbana torna-se elemento ativo quando a constelação desses aspectos históricos e literários articulados passa a modular de modo determinante a nossa literatura. Isto é, quando a articulação entre acumulação literária e acumulação histórica implica um redimensionamento de mesma experiência histórica e literária.

As linhas gerais desse andamento na nossa literatura, que estou sugerindo de modo muito genérico e esquemático, talvez nos permitam compreender alguns aspectos importantes de obras de escritores que surgiram mais ou menos próximos aos anos 30. Aspectos esses que talvez também estejam na gênese da composição de alguns poetas como Manuel Bandeira, Carlos Drummond de Andrade e mais adiante João Cabral. Na prosa de ficção, ainda que com dicções narrativas e perspectivas de mundo bastante diferentes entre si, algo da obra de Graciliano Ramos, José Lins do Rego, Dyonelio Machado, Cyro dos Anjos e Lúcio Cardoso reflete, num conteúdo formalmente estruturado, o trânsito dessa experiência do esgotamento rural que vai como que desembocar em representações diferentes da vida urbana brasileira, as quais despontam gradativamente no horizonte.

Gostaria de destacar alguns traços, algumas características desta experiência de trânsito. Se fosse possível resumir numa imagem a figura do sujeito ficcional desta experiência, creio que ela está na imagem drummondiana dofazendeiro do $a r .{ }^{6}$ Note-se que o espaço aparentemente livre para o qual se projeta esse sujeito uma espécie de não-lugar para o qual ele se lança ou se encontra, no ar - se contrapõe fortemente à natureza, ao caráter substantivo que diz algo do seu ser ou de sua posição de classe mesma - a sua condição de fazendeiro, de indivíduo ligado à terra, à propriedade rural $\mathrm{e}$ a suas formas de pensar, de sentir e de se relacionar. Parece relativamente claro que este sujeito se enuncia a partir do desenraizamento, contraditório e paradoxal, de sua experiência social. Experiência essa (rural) que, se deixou de vigorar no plano da vivência/experiência histórica concreta, sugere não ter se esgotado como experiência intelectual e espiritual, como sentimento do mundo. Disso resulta a figuração de uma trajetória pessoal e social de temporalidade bifronte, contraditória e fissurada, a qual, como sugeri acima, já está presente na constituição interna da imagem-síntese do sujeito ficcional que dá expressão a essa

5 Ibid., p. 153.

6 Roberto Schwarz já havia chamado atenção para a importância desse personagem na literatura brasileira no século XX, ao final do seu ensaio "Cultura e política, 1964-1969", In: O pai de família e outros estudos. 2. ed. Rio de Janeiro: Paz e Terra, 1992. p. 92. 
experiência, o fazendeiro do ar. Essa experiência da temporalidade bifronte e contraditória pode ganhar tintas mais explícitas num belo poema como "Episódio", do mesmo Drummond, que se encontra no livro a Rosa do povo. Diz o poema:

\author{
Manhã cedo passa \\ à minha porta um boi. \\ De onde vem ele \\ se não há fazendas? \\ Vem cheirando o tempo \\ entre noite e rosa. \\ Pára a minha porta \\ sua lenta máquina. \\ Alheio à polícia
anterior ao tráfego
ó boi, me conquistas
para outro, teu reino. \\ Seguro teus chifres: \\ eis-me transportado \\ sonho e compromisso \\ ao País Profundo. ${ }^{7}$
}

Já no plano da narrativa, esse entrecruzamento de temporalidades - um tempo rural, residual, morto ou meio fantasmagórico, por um lado, e por outro um tempo urbano, moderno - parece ser um dos aspectos constituintes de algumas obras de ficção dos anos 30. Procurei analisar este problema num outro trabalho a partir do exame das obras $O$ amanuense Belmiro, de Cyro do Anjos, Angústia, de Graciliano Ramos, e Os ratos, de Dyonelio Machado. ${ }^{8}$ Mas interessa sublinhar, para o que tenho em vista, neste momento, que os sujeitos ficcionais destas narrativas, como o sujeito lírico drummondiano, experienciam o mundo urbano como uma espécie de exílio da vida, de inadaptação profunda à urbe. Não que em algum momento esses personagens tenham tido um locus seu, que se traduzisse em sentimento de pertença.

7 ANDRADE, Carlos Drummond de. Reunião. 8. ed. Rio de Janeiro: José Olympio, 1977. p. 94.

8 Sobre o assunto ver $O$ romance da urbanização, de Fernando C. Gil. Porto Alegre: EDIPUCRS, 1999. 
Se por acaso este lugar existiu, na melhor das hipóteses, ele retorna como uma espécie de lirismo escapista - vinculado ao passado rural -, mas sempre circunscrito e referido ao emparedamento da situação do presente na cidade. O sentimento dessa experiência pode ser sintetizada nas palavras do personagem Belmiro Borba, quando ele diz: "Minha vida parou, e desde muito tempo me volto para o passado, perseguindo imagens fugitivas de um tempo que se foi". ${ }^{9}$ Esta mesma sensação também pode estar presente em tom mais amargo e ressentido num personagem como Luís da Silva, de Angústia, quando declara: "Entro no quarto, procuro um refúgio no passado. Mas não me posso esconder inteiramente nele. Não sou o que era naquele tempo. Falta-me tranqüilidade, falta-me inocência, estou meio um molambo que a cidade puiu demais e sujou". ${ }^{10}$

A minha hipótese, então, é a de que o aparecimento da experiência urbana na ficção brasileira encontra-se como que cifrado a partir de signos que apontam para a irrealização dessa experiência urbana. ${ }^{11}$ É uma experiência que surge, desde o seu início, para não se constituir, ou melhor, é uma experiência que se enuncia a partir de sua má constituição, de sua constituição problemática. Neste ponto, poderia alguém contra-argumentar, de modo bastante plausível, que sujeitos cindidos, "alheios a si mesmos e distanciados do mundo urbano que não reconhecem como seu, mas como algo separado, estranho e hostil", ${ }^{12}$ caracterizam mesmo o modo de ser da experiência individual e social urbana, moderna e também contemporânea dominado pelo capital e pela mercadoria, talvez desde a ficção de Balzac e a poesia de Baudelaire. A objeção de um modo genérico é válida, mas estou tentando chamar a atenção para o fato de que há aspectos específicos a considerar na formação e expansão das sociedades urbanas e, por conseqüência, nas formas literárias que dão expressão a experiências urbanas diversificadas.

Assim, vale sublinhar o seguinte ponto: a experiência urbana entrou em nossa literatura sorrateiramente, pela porta dos fundos, como se ali não quisesse estar ou ali estivesse a contragosto, dada menos pela expansão das formas de sociabilidade e pelo ritmo da vida urbana e moderna, e muito mais pelo esgotamento de nossa experiência oligárquico-latifundiária. Não para menos essa experiência urbana dos anos 30, que diria inaugural, tem sua ambientação ficcional em capitais de província, como, por exemplo, Belo Horizonte, Porto Alegre, Maceió, e menos

9 ANJOS, Cyro dos. O amanuense Belmiro. 11. ed. Rio de Janeiro: José Olympio, 1980. p. 15.

10 RAMOS, Graciliano. Angústia. São Paulo: Círculo do Livro, s.d. p. 16.

11 GIL, op. cit. p. 47.

12 BUENO, André. Sinais da cidade: forma literária e vida cotidiana. In: O imaginário da cidade. Brasília: Editora Universidade de Brasília/São Paulo: Imprensa Ofícial do Estado, 2000. p. 89. 
em cidades que eram ou que se pretendiam metrópoles, como Rio de Janeiro e São Paulo. A contigüidade de experiências históricas diversas, ou seja, a passagem de uma experiência de mundo rural para um mundo urbano - que se articula numa espécie de temporalidade dual sincronizada e articulada num mesmo espaço -, associada a um fluxo externo de avanço e de modismos mais precário, parece exacerbar o senso dos contrários dessa experiência social e literária nas pequenas capitais de província. Curiosamente, ali onde nada parece acontecer, descortina-se um lugar estratégico para se perscrutar uma experiência literária específica, que também diz muito de uma certa recorrência do andamento de nossa história social. No caso, trata-se da estilização de uma fratura histórica, em que o novo, o moderno, em suma, aquilo que aqui se tem chamado de experiência urbana moderna entra em cena, em nossa literatura, ao problematizar e tomar consciência de um campo de experiência em liquidação. Ao falar da força residual desse passado (desse mundo rural), essas narrativas estruturam, formalmente, em diferentes planos de sua composição, a precariedade, a fragilidade constitutiva dessa mesma experiência urbana como um tempo de experiência integrado à modernidade.

Pode-se dizer, portanto, que é a partir da figuração dessa fraqueza e do sujeito ficcional que a encarna e a sintetiza que a paisagem urbana vai se mostrando como elemento dominante em nossa imaginação literária. Fraqueza, bem entendida, da qual emana a força estética de certas narrativas, uma vez que estiliza uma experiência complexa e contraditória centrada na idéia e num sentimento de paralisia, de imobilismo que vai caracterizar todo o andamento dessa prosa ficcional e, por extensão, o cotidiano urbano de figuras como Belmiro Borba, Naziazeno Barbosa e Luís da Silva, não podendo deixar de mencionar ainda, como espécie de prelúdio deste processo, o personagem Isaías Caminha, de Lima Barreto. ${ }^{13}$ Ao contrário do que supunham alguns de nossos vanguardistas de 22 e a contrapelo também do que pode sugerir a lógica de certas formações urbanas modernas, nosso ingresso na experiência urbana, no plano da ficção, não se deu sob signo da velocidade, do dinamismo, da violência do movimento, da experiência do choque e do caráter multiforme dessa experiência. De modo singular e paradoxal, a cidade instala-se na nossa ficção para mostrar que todo o movimento no seu interior se traduz em efeito de imobilidade e paralisia. Imobilidade que somente será rompida quando, algumas décadas mais tarde, a porta da frente de nossa literatura urbana - e não só dela, claro - for turbilhonada e arrombada de vez pelo que chamaria de experiência da

13 A respeito deste personagem, ver o artigo "Uma palha na cidade", de Irenísia Torres de Oliveira, neste dossiê. 
GIL, F. C. Experiência urbana e romance brasileiro

destrutividade, a qual está presente nas narrativas contemporâneas de Rubem Fonseca, de Sérgio Sant'Ana, Dalton Trevisan e Murilo Rubião, entre outros. Mas isso já é um outro capítulo desta mesma história.

\section{RESUMO}

Este trabalho analisa a especificidade da experiência urbana moderna no romance brasileiro, localizando a sua entrada em cena na forma ficcional nos anos de 1930 .

Palavras-chave: Romance brasileiro, experiência urbana.

\section{ABSTRACT}

This work analyzes the specificity of the modern urban experience in the Brazilian novel, locating its entrance scene in the fictional form in the years of 1930.

Key-words: Brazilian novel, urban experience.

\section{REFERÊNCIAS}

ANDRADE, Carlos Drummond de.Reunião. 8. ed. Rio de Janeiro: José Olympio, 1977.

ANJOS, Cyro dos. O amanuense Belmiro . 11. ed. Rio de Janeiro: José Olympio.

BUENO, André. Sinais da cidade: forma literária e vida cotidiana. In: LIMA, Rogério; FERNANDES, Ronaldo Costa. O imaginário da cidade . Brasília: UnB, São Paulo: Imprensa Oficial do Estado, 2000.

CANDIDO, Antonio. A educação pela noite. São Paulo: Ática, 1987.

GIL, Fernando C. O romance da urbanização. Porto Alegre: EDIPUCRS, 1999.

RAMOS, Graciliano. Angústia. São Paulo: Círculo do Livro, s.d.

SCHWARZ, Roberto. O pai de família e outros estudos. 2. ed. Rio de Janeiro: Paz e Terra, 1992. Um mestre na periferia do capitalismo. São Paulo: Duas Cidades, 1990. . Ao vencedor as batatas. São Paulo: Duas Cidades, 1981. 